\title{
Issues Related to Transit Network Design Problem
}

\author{
Mahmoud Owais \\ Assistant Professor at Civil \\ Faculty of Engineering, Civil \\ Department Assiut
}

\begin{abstract}
Public Transit (P.T) is very important means to reduce traffic congestions, to improve urban environmental conditions and consequently affects people social lives. Planning, designing and management of P.T are the key issues for offering a competitive mode that can compete with the private transportation. These transportation planning, designing and management issues are addressed in the Transit Network Design Problem (TNDP). It deals with a complete hierarchy of decision making process. It includes strategic, tactical and operational decisions. The main body of TNDP is two stages, namely; route design stage and frequency setting. The TNDP is extensively studied in the last five decades; however the research gate is still widely open due to its many practical and modeling challenges. In this paper, a comprehensive background is given to illustrate the issues and challenges related to the TNDP to help in directing the incoming researches towards the untouched areas of the problem.
\end{abstract}

\section{General Terms}

Transportation - Computer applications

\section{Keywords}

Transit Planning - Network Design - Frequency setting Urban Planning.

\section{INTRODUCTION}

The transit planning and operation process commonly includes five basic activities, usually performed in sequence: (1) network route design, (2) frequency setting, (3) timetable development, (4) vehicle scheduling, and (5) crew scheduling [1-3]. The output of each activity positioned higher in the sequence becomes an important input for lower-level decisions. In practical, first and second component are combined under the Transit Network Design Problem (TNDP).

TNDP is the most important component in Transit planning, in which the overall cost of the public transportation system highly depends on it. The TNDP aims to design a set of bus routes and manage these routes operation in an efficient manner for both users and operators. Different system functions and targets, required for each group of participants, have to be met through the solution methodology. TNDP, stated simply, relates to the determination of a set of routes defined over the street network with their corresponding schedules to deal with demand trips [4].

There are some basic concepts should be clarified before proceeding on. These concepts are recognized by transit research community. They would help in getting a good grasp of the problem.

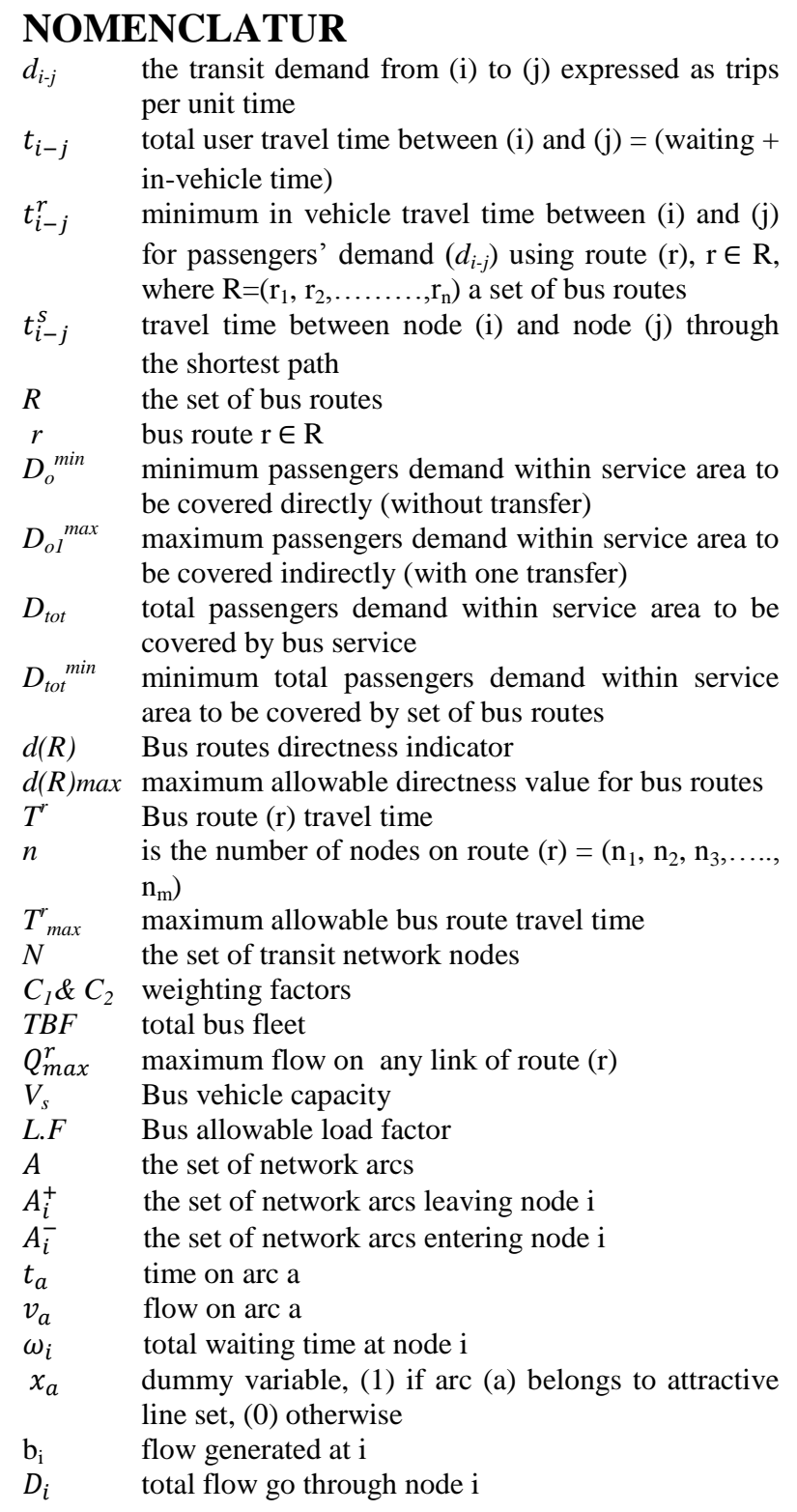

a) Demand coverage classification: The demand for each node pair $\left(d_{i-j}\right)$ is classified as -0- transfer, -1- transfer, -2transfer or unsatisfied demand. Node pair demand $d_{i-j}$ is considered to be satisfied directly (i.e. 0-transfer demand), if there is, at least, one bus route traversed both node (i) and (j). $d_{i-j}$ is considered to be satisfied with -1 - transfer, if , at least, one bus route traversed node (i) intersected with other route traversed node $(j) . d_{i-j}$ is considered to be satisfied with -2- transfer, if , at least, there is one bus 
route intersected with route traverse (i) and route traverse (j). Remaining node pairs demand are considered unsatisfied demand. In Fig. 1, it is obvious that, $d_{1-2}$ is -0transfer demand, $d_{1-3}$ is -1- transfer demand and $d_{1-5}$ is -2transfer demand.

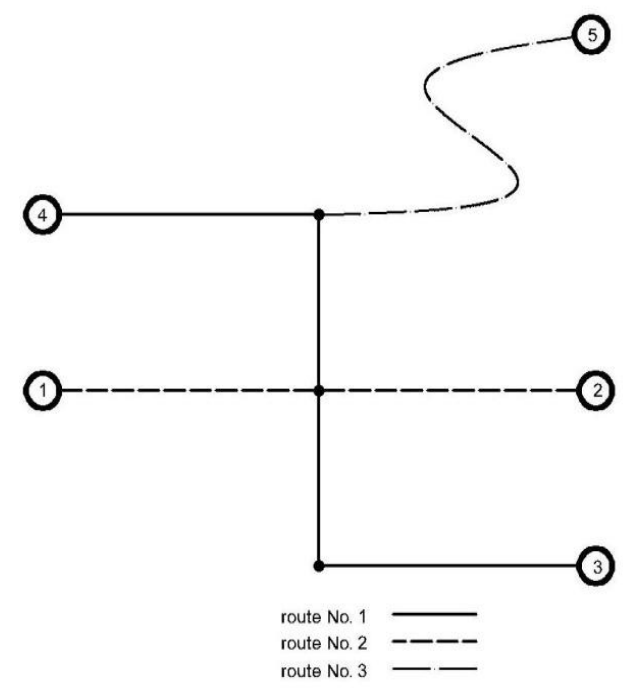

Fig. 1 Example of different demand coverage types

b) Route directness $(d(R))$ : it is an indicator to measure the bus route deviation from the shortest path among main transit nodes pairs since; $d(R)=1$ indicates that all bus users would take the shortest path along their travel between the origin and destination. Value of $d(R)$ which exceeds one, it would indicate the delay caused by the set of bus routes to all users.

$d(R)=\sum_{i} \sum_{j} d_{i-j} \times \frac{t_{i-j}^{r}}{t_{i-j}^{s}} / \sum_{i} \sum_{j} d_{i-j}$

where; $\sum_{i} \sum_{j} d_{i-j}$ represents network Total Demand.

a) Transit route length: it is measured, either in kilometers or in minutes. It is more appealing and practical to deal with routes length in time units. There is a constraint on maximum transit route length based on either heuristic guidelines, past experience or common practice accepted by transit planners. Longer bus routes may cause bus driver fatigue and consequently result in safety hazards. Maximum round trip should not exceed 2 hours [5].

b) Maximum link flow: After passenger assignment on the transit network, each bus route (r) would have a maximum link flow $\left(\mathrm{Q}_{\max }^{\mathrm{r}}\right)$. It is considered the ruler in setting bus route frequency and bus size to accommodate this maximum flow. Since in large networks, it is too difficult to keep track of all link flows. For each bus route, $Q_{\max }^{\mathrm{r}}$ could be approximately obtained by multiplying the route's directly satisfied flow with the flowing factors;

$Q_{\text {max }}^{r}=\left(1+f_{t f}\right) \times f_{l f} \times D_{o}^{r}$

$f_{t f}$ is transferring flow factor which accounts for the transferring flow on the route. $f_{l f}$ is maximum link flow fraction and it would be estimated as flows;

$$
\begin{array}{ll}
f_{l f}=\frac{n}{2(n-1)} & \text { if } \mathrm{n} \text { is even } \\
f_{l f}=\frac{\mathrm{n}+1}{2 \mathrm{n}} & \text { if } \mathrm{n} \text { is odd }
\end{array}
$$

Where; $D_{o}^{r}$ is direct demand satisfied by route (r) and $\mathrm{n}$ is the number of nodes of bus route [6]

c) Service Frequency: it is simply referred to the number of buses running on a certain route per hour. The most commonly used service frequencies in the transit industry can be grouped into three categories; supply frequency, policy frequency, and demand frequency. Supply frequency is dependent on the operator's resources including limited fleet size. It is the maximum frequency that the operator can provide under current resource and economic constraints. Demand frequency is determined by transit demand. This frequency is the minimum frequency that provides just enough capacity to meet the demand on the maximum link flow so that on the other links of this route, the demand is always less than the capacity. Policy frequency can serve as a lower bound and an upper bound for service frequency. It reflects transit network operation constraints and is usually used by transit operators when the demand is too high or too low. In the real world, as well as in the bus transit route network design process, the demand frequency approach is preferred because it reflects the purpose of transit operations, which is to provide customer- oriented service. Furthermore, the maximum bus route frequency and the minimum bus route frequency have been chosen as 30 bus/hr and 6 bus/hr [7, 8].

d) Bus route capacity: its concept differs from the ordinary concept of street-link capacity. The route capacity is based on the idea that the route service frequency shouldn't exceed a predefined value and buses have a limit seating capacity, thus the maximum allowable flow on bus routelink ;

$X_{a} \leq L . F \times f_{\max } \times V_{s}$

Where; $X_{a}$ is the link passenger flow.

e) Transfer penalty: it is the term which reflects transit users inconvenience to make transfer. Transfer penalty is measured by equivalent in-vehicle time units. Penalty values are likely to vary across different geographic areas and change with demographics, socioeconomics, topography, clim-ate, quality of transfer facilities and etc.

f) User Cost: Total user cost can be easily expressed by the following expression;

$U C_{k}=\varphi_{a}(T A T)+\varphi_{w}(T W T)+\varphi_{v}(T B T+T I V T)$

Where the terms in (6) represent respectively; users costs associated with mode $(\mathrm{k})$ of travel, total passengers access time in minutes, total passengers waiting time in minutes, total passengers boarding time in minutes, total passengers in vehicle time in minutes. Whereas $\varphi_{\mathrm{a}}, \varphi_{\mathrm{w}}, \varphi_{\mathrm{v}}$ are weighting values of access, waiting and in-vehicle time.

g) Operator cost: the main cost $\left(O C_{k}\right)$ is the total bus fleet required for operating. Vehicles operating costs for vehicle type (k) are taken as the sum of the direct costs plus the indirect costs for the given input parameters such as:

The direct costs; (DC) are considered as three factors:

1. Costs of direct travelled distance (L) in kilometer; (CK).

2. Costs associated with time spent at bus stops; (CS).

3. Costs associated with personnel costs; (CP). 
Indirect costs; $(\mathrm{CF})$ were found in other studies to be nearly $12 \%$ of the direct costs these costs include maintaining buses license, insurance ... etc [9].

Up to now, there is no general and solvable (in the same time) mathematical formulation for the TNDP; the reason is the high degree of problem complexity. There are five main sources of complexity that often preclude finding a unique optimal solution for TNDP, namely; problem formulation, Non-linearity and non-convexity, combinatorial complexity, NP-hard and multi-objective nature of TNDP [4, 10-12]. However, it can be derived a general mathematical formulation to clarify TNDP objectives;

$$
\begin{gathered}
\min C_{1} \sum_{i \in N} \sum_{j \in N} d_{i-j} \times t_{i-j}+C_{2} \sum_{r \in R} f_{r} \times T^{r} \\
\text { s.t. }
\end{gathered}
$$

$$
\begin{aligned}
& D_{o}(R) \geq D_{o}^{\min } \\
& D_{o l}(R) \leq D_{o l}^{\max } \\
& D_{t o t}(R)=D_{o}+D_{o l} \geq D_{\text {tot }}^{\text {min }} \\
& d(R)=\sum_{i} \sum_{j} d_{i-j} \times \frac{t_{i-j}^{r}}{t_{i-j}^{s}} / \sum_{i} \sum_{j} d_{i-j} \leq d(R)_{\text {max }} \\
& T^{r}=\sum_{i}^{m-1} \sum_{j=i+1}^{m} t_{i-j}^{r} \leq T_{\text {max }}^{r} \\
& \sum_{r \in R} f_{r} \times T^{r} \leq T B F \\
& \frac{Q_{\text {max }}^{r} \leq L . F}{f_{r} \times V_{s}} \leq L
\end{aligned}
$$

Equation (7) represents the general objectives of TNDP. First term concerns with users costs. Second term concerns with operator's cost. $\mathrm{C} 1 \& \mathrm{C} 2$ weighting factors reflect the relative importance of two cost components. By varying $\mathrm{C} 1 \& \mathrm{C} 2$, one can generate different trade-offs between users and operator costs. (8 - 10) represent demand coverage constraints. Inequality (11) represents route directness. (12-14) reflect the operational parameters.

\section{STATE OF ART}

TNDP is a complete hierarchal multi-disciplinary process, see Fig. 2. It shows the general framework of the TNDP. The Main data are the demand trips between different traffic zones of the city and the street network structure. Passengers' demand for travel among Origin - Destination (O/D) locations represents the need of transport system. Each zone has associated with one zone centroid and group of passengers with their desired (O/D) trips which are concentrated at zone centroid. Transit modes supply services are routed in an environment to pick - up and deliver passengers demand among - what is called - Transit (O/D) locations through selection of efficient bus routes from a given street network representation.

For certain zone, the number of O-D trips is a product of population, employment, land-use and transit (expected) level of service in this zone. Demand is an essential element for the TNDP. The more precise transit O/D demand estimation, the more adequate TNDP solution is obtained. There are two approaches for transit $(\mathrm{O} / \mathrm{D})$ matrix estimation. First approach is to use the traditional four-step travel forecasting model. This approach is used for networks that would be designed from scratch (new towns without any existing transit systems). Second approach, is to use counting data at existing bus stops. Although, literature review concerning auto O-D estimation is extensive [13, 14], there are few works concerning transit O-D estimation [15].

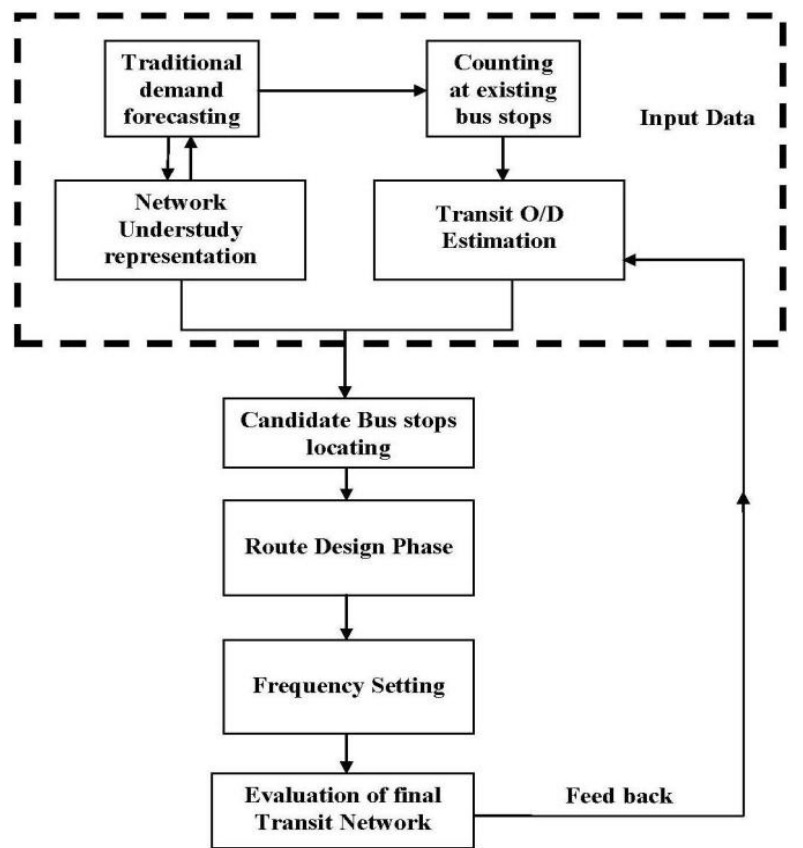

Fig. 2: the general framework of the TNDP

Previously, two approaches for transit demand are tackled. The first approach considers demand fixed and independent of service quality. Whereas the second approach considers demand variable and dependent on simultaneous distribution - modal split. However, the variable demand assumption is more appealing, the first assumption is common used for the purpose of simplicity $[16,17]$.

Two basic levels of the street network representation could be classified for The TNDP. First type is zone centroid level where each zone demand is aggregated at its centroid. Second level is node level where each node in the network is considered as a potential bus stop (origin). It isn't practical solution to consider all these nodes as bus stops, so a filtering stage should be provided to select candidate bus stops (nodes) according to each node demand and maximum allowable walking distance $[18,19]$.

Route design stage is the essential part of The TNDP. It constitutes the strategic to tactical planning term in the design process. It forms the combinatorial complexity of the problem [20 - 25]. Route connectivity represents the major obstacle in mathematical formulation for the TNDP [26]. Three basic approaches for route construction would be defined, namely; graph based methods, mathematical based methods and greedy based methods.

Graph based methods use the network graph representation to generate routes according to shortest paths or k-shortest paths strategies [27, 28]. Mathe-matical based methods use these techniques found in Travel Salesman Problem (TSP). TSP is one of the most widely studied combinatorial optimization problems. However, its statement is deceptively simple: a salesman seeking the shortest tour through $(\mathrm{N})$ clients (cities) that allows each client to be visited once and only once [2931]. It is used in some researches to investigate its applicability for bus routes generation [32-34]. Greedy based methods use a node as start node, then they begin to construct route by connecting a node adjacent to the considered node. This process is repeated, until the route construction is completed, as shown in Fig 3. The next node to visit is selected according to a strategy [35-37]. 


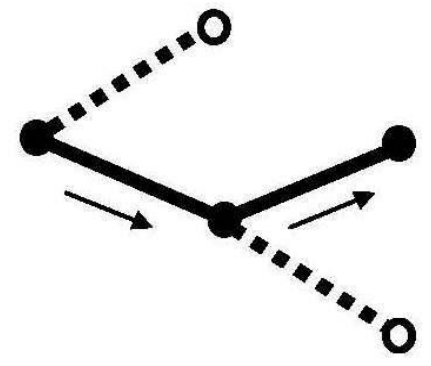

Fig. 3: Greedy based methods

Improvements may be introduced to enhance the routes under construction. Heuristics are used in $[6,7,11],[20,38,39]$ to seed the routes with additional nodes. Genetic Algorithm is used in [40] to improve nodal composition of the constructed routes.

Even if the problem of route construction is solved, the transit route network is still cumbersome. In other words, we need some routes which would constitute the transit network to achieve some objectives. Operator cost, user cost and demand coverage are the main objectives to be regarded. This may be called route selection problem. Let us consider the following (m-n) matrix in Fig. 4.

In this set covering matrix, columns (n) represent the generated routes and rows $(\mathrm{m})$ represent the O-D pairs have to be covered directly by the network. $a_{m-n}$ takes 1 if O-D pair (m) covered by route (n), 0 otherwise. The question risen here is how to select the minimum number of routes to achieve the concerned objectives [41].

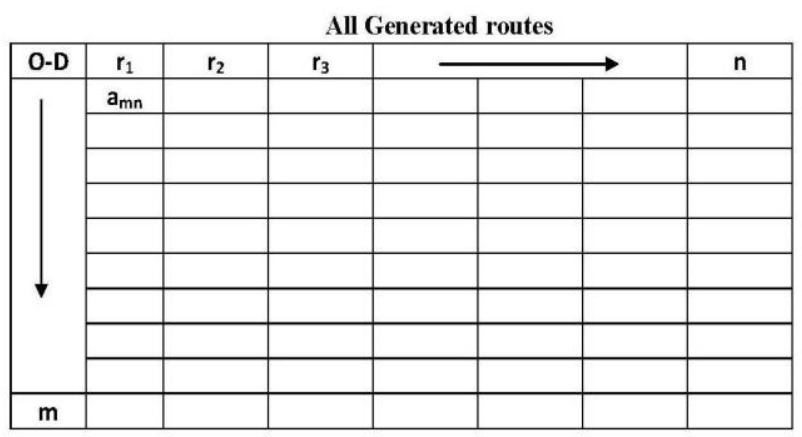

Fig. 4: Transit route Network selection problem

Frequency setting constitutes the tactical to operational term in the TNDP. The planner is interested in setting bus frequency on the network in the most precise way regarding which routes to be used and loaded, according to passengers' interest. The problem arisen here is a transit passenger assignment problem. It is the major component in transit route frequency setting. It would be defined as the query of passenger flows on transit networks segments. Passenger assignment is a process of predicting passengers' behavior in selecting bus routes according to route time length and bus frequency for each bus route [14].

This makes frequency setting problem a bi-level optimization. It stems from the trend to balance between operator's decision (upper level) and users reaction (lower level). Upper level would concern with route frequency setting and lower level would concern with the transit assignment model [42, 43]. Also, it may be tried to take into account the interaction between supply side and demand side similar to continuous network design problem [44].
Transit passengers in many cases have to deal with overlapping bus route with some routes sharing sections and common stops. This problem is a sub-problem of transit passenger assignment, called common-lines problem. Various assumptions and studies are made in order to track passengers' behavior towards a given supply of transit service [45-49].

The concept of clever passenger may be considered as the basis of all transit assignment models. Passengers would minimize the sum of waiting time and in-vehicle time in their boarding strategies. If there is more than one route serving an origin node (i) and destination node (j). This would lead the passengers, who wish to travel from (i) to (j), to determine a sub-set of bus routes (attractive lines) boarding the first incoming bus of these routes. Mathematically, it could be formulated as follows;

$$
\begin{array}{ll}
\operatorname{minimize} \sum_{a \in A} t_{a} v_{a}+\sum_{i \in N} \omega_{i} & \\
\text { s.t. } & \\
\sum_{\mathrm{a} \in \mathrm{A}_{\mathrm{i}}^{+} \mathrm{v}_{\mathrm{a}}-\sum_{\mathrm{a} \in \mathrm{A}_{\mathrm{i}}^{-}} \mathrm{v}_{\mathrm{a}}=\mathrm{b}_{\mathrm{i}}} & \forall \mathrm{i} \in \mathrm{N} \\
\omega_{\mathrm{i}}=\frac{\mathrm{D}_{\mathrm{i}}}{\sum_{\mathrm{a} \in \mathrm{A}_{\mathrm{i}}^{+}} \mathrm{f}_{\mathrm{a}} \mathrm{x}_{\mathrm{a}}} & \forall \mathrm{i} \in \mathrm{N} \\
\mathrm{v}_{\mathrm{a}} \geq 0 & \forall \mathrm{a} \in \mathrm{A}_{\mathrm{i}}
\end{array}
$$

The model in (15) states that equilibrium occurs when all users succeed in minimizing both travel and expected waiting time. It is worth noting; that expected waiting time is equal to the inverse of line(s) frequency. (15-18) are mixed integer non-linear model which is difficult (impossible) to be solved for large scale networks. Other modeling difficulties are three fold; forcing the number of allowed transfer, incorporating the transfer penalty and congestion modeling.

In the stated model, users may do unlimited number of transfers opposing to the reality. Incorporating transfer penalty leads to expand the network to incorporate transfer links associated with transfer penalty value. Congestion refers to the potentiality that user may not board the first incoming bus (of attractive lines) due to congestion. Many studies have attempted to overcome these aspects [18, 42, 50, 51]

In [6, 11], they developed Network Analysis Procedure (NETAP) to assign passengers through iterative procedure. It alleviated the complexity of the mathematical model; however it has no theoretical prove to reach a convergence state and many simplifications are made. There are limited works on heuristics transit assignment models like [36, 40].

\section{CONCLUSION}

In this paper, the state of art of the TNDP is reviewed to expand the knowledge of the problem issues and challenges among recent researchers. It is obvious that there are still suspended items which need extensive studies. Route construction techniques and selection procedures are still widely open for further studies. Candidate bus stops problem is received little attention in the literature review. It needs more investigation about the way of its incorporation in the TNDP design process. Accurate and dynamic transit O/D predictors are also worth more investigation. The behavior of users who would transfer needs more clarification and modeling. In general terms, a global solution methodology for the TNDP is a challenging task besides none of the review studies have claimed reaching the optimal solution of the problem. 


\section{ACKNOWLEDGMENT}

I would like to thank Eng.I Marwa Abd El-Gwad for her valuable assistant and support.

\section{REFERENCES}

[1] Ceder, A. and N.H.M. Wilson, Bus network design. Transportation Research, 1986. 20B(4): p. 331-344.

[2] Ceder, A., Public transport scheduling. In Handbooks in Transport - Handbook 3: Transport Systems and Traffic Control. 2001: Elsevier Ltd.

[3] Ceder, A., Urban transit scheduling: framework, review, and examples. ASCE Journal of Urban Planning and Development, 2002. 128(4): p. 225-244.

[4] Chakroborty, P., Genetic Algorithms for Optimal Urban Transit Network Design. Computer - Aided Civil and Infrastructure Eng. Blackwell Publishing, Malden MA 02148, USA, 2003. 18: p. 184-200.

[5] NCHRP Synthesis of Highway Practice 69 (1980), Bus Route and Schedule Planning Guidelines, Transportation Research Board, National Research Council, Washington, D.C.

[6] Shih, M.-C. and H.Mahmassani, A design methodology for bus transit networks with coordinated operation, in SWUTC/94/60016-1, Center for Transportation, Bureau of Engineering Research. 1994, the University of Texas at Austin, Austin, Texas.

[7] Baaj, M.H. and H.Mahmassani, Hybrid Route Generation Heuristic Algorithm for the Design of Transit Networks. Transportation Research Part C: Emerging Technologies, 1995. 3(1): p. 31-50.

[8] Fan, W., Optimal Transit Route Network Design Problem: Algorithms, Implementations, and Numerical Results. 2004, Graduate School of the University of Texas at Austin.

[9] dell'Olio, L., A. Ibeas, and F.R. Díaz, Assigning vehicles types to a bus transit network. TRB 2009 Annual Meeting CD-ROM, 2008.

[10] Garey, M.R. and D.S. Johnson, Computers and intractability: A guide to the theory of np-completeness. W.H. Freeman, 1979: p. 5-1045.

[11] Baaj, M.H., The Transit Network Design Problem: An AI-Based Approach, in Department of Civil Engineering, University of Texas, Austin, Texas. 1990.

[12] Zhao, F. and X. Zeng, Optimization of transit route network, vehicle headways and timetables for large-scale transit networks. European Journal of Operational Research, 2008. 186: p. 841-855.

[13] 13. YANG, H., Y. IIDA, and T. SASAKI, AN ANALYSIS OF THE RELIABILITY OF AN ORIGINDESTINATION TRIP MATRIX ESTIMATED FROM TRAFFIC COUNTS. Transpn. Res.-B, 1991. 25(5): p. 351-363.

[14] YANG, H. and J. ZHOU, OPTIMAL TRAFFIC COUNTING LOCATIONS FOR ORIGINDESTINATION MATRIX ESTIMATION. Transpn Res.-B, 1998. 32(2): p. 109-126.

[15] Li, Y. and M.J. Cassidy, A generalized and efficient algorithm for estimating transit route ODs from passenger counts. Transportation Research Part B: Methodological, 2007. 41(1): p. 114-125.

[16] Hasselstrom, D., Public Transportation Planning -- A Mathematical Programming Approach, Ph.D. thesis, Department of Business Administration, University of Gothenburg, Sweden. 1981

[17] VanNes, R., R. Hamerslag, and B.H. Immer, The Design of Public Transport Networks. Transportation Research Record, No. 1202, Transportation Research Board, Washington, D.C., 1988. 74-83.

[18] Gan, A. and F. Zhao, Optimization of Transit Network to Minimize Transfers. Final Report, Research Office Florida Department of Transportation 605 Suwannee Street, MS 30 Tallahassee FL 32399-0450, 2003.

[19] Sheffi, Y., Urban Transportation Networks Equilibrium Analysis with Mathematical Programming Methods. 1985, Inc. Englewood Cliffs, New Jersey. p. 1-20.

[20] Mauttonw, A. and M. Urquhart, A route set construction algorithm for the transit network design problem. Computers and Operations Research, 2009. 36(8): p. 2440-2449.

[21] Owais, M. and G. Moussa, A Novel Solution Methodology for Transit Route Network Design Problem. International Journal of Civil, Architectural Science and Engineering, 2014. 8(3): p. 658-665.

[22] Owais, M., et al., Simple and Effective Solution Methodology for Transit Network Design Problem. International Journal of Computer Applications, 2014. 89(14): p. 32-40.

[23] Owais, M.M.A., Investigating Optimal Bus Routes Planning and Operation in Urban Areas. 2014, Assiut University, Faculty of Engineering, Civil Department

[24] MM, O., et al., OPTIMAL CIRCULAR BUS ROUTES PLANNING FOR TRANSIT NETWORK DESIGN PROBLEM IN URBAN AREAS. Journal of Engineering Sciences, 2013. 41

[25] Owais, M., et al., OPTIMAL FREQUENCY SETTING FOR CIRCULAR BUS ROUTES IN URBAN AREAS Journal of Engineering Sciences, 2013. 41(5): p. 1796 1811.

[26] Chakroborty, P., K. Deb, and R.K. Sharma, Networkwide optimal scheduling of urban transit networks using genetic algorithms. Transportation Planning and Technology, 2001. 24(3): p. 209-26.

[27] Dijkstra, E.W., A Note on Two Problems in Connection with Graphs. Numeriche Mathematik, 1959. 1: p. 269271.

[28] Yen, J.Y., Finding the K Shortest Loopless Paths in a Network. Management Science, 1971. 7(11): p. 712-716.

[29] Laporte, G., The Traveling Salesman Problem: An overview of exact and approximate algorithms. European Journal of Operational Research, 1992. 59: p. 231-247.

[30] Dorigo, M., M. Birattari, and T. Stutzle, Ant Colony Optimization. IEEE COMPUTATIONAL INTELLIGENCE MAGAZINE, 2006: p. 28-39.

[31] Miller, C.E., A.W. Tucker, and R.A. Zemlin, Integer programming formulation of traveling salesman problems. Journal of ACM, 1960. 7: p. 326-9. 
[32] Ceder, A. and S. Jerby, Optimal Routing Design for Shuttle Bus Service. Transportation Research Record: Journal of the Transportation Research Board, 2006: p. 14-22.

[33] Ceder, A., Public Transit Planning and Operation. 2007: Elsevier Ltd.

[34] Lownes, N.E. and R.B. Machemehl, Exact and heuristic methods for public transit circulator design. Transportation Research Part B, 2010. 44(2): p. 309-318.

[35] Yu, B., Z.Z. Yang, and B.Z. Yao, An improved ant colony optimization for vehicle routing problem. European Journal of Operational Research, 2009. 196(1): p. 171-176.

[36] Yu, et al., An ant colony optimization model: the period vehicle routing problem with time windows. Transportation Research Part E, 2011. 47(2): p. 166-181.

[37] Nikolic, M. and D. Teodorovic, Transit network design by Bee Colony Optimization. Expert Systems with Applications, 2013. 40: p. 5945-5955.

[38] Lampkin, W. and P.D. Saalmans, The Design of Routes, Service Frequencies and Schedules for a Municipal Bus Undertaking: A Case Study. Operation Research Ouarterly, 1967. 18: p. 375-397.

[39] Baaj, M.H. and H.Mahmassani, An AI-Based Approach for Transit Route System Planning and Design. Journal of Advance Transportation, 1991. 25(2): p. 187-210.

[40] Szeto, W.Y. and Y. Wu, A simultaneous bus route design and frequency setting problem for Tin Shui Wai, Hong Kong. European Journal of Operational Research, 2011. 209(2): p. 141-155.

[41] Ceder, A. and Y. Israeli, User and Operator Perspectives in Transit Network Design. Journal of the Transportation Research Board, 2007. 1623: p. 3-7.

[42] Constantin, I. and M. Florian, Optimizing Frequencies in a Transit Network: a Nonlinear Bi-level Programming
Approach. International Transactions in Operational Research, 1995. 2(2): p. 149-164.

[43] Mesbah, M., et al., Optimization of transit priority in the transportation network using a decomposition methodology. Transportation Research Part C: Emerging Technologies, 2011. 19(2): p. 363-373.

[44] Gao, Z., H. Sun, and L. Shan, A Continuous Equilibrium Network Design Model and Algorithm for Transit Systems. Transportation Research Part B: Methodological, 2004. 38(3): p. 235-250.

[45] Chriqui, C. and P.Robillard, Common Bus Lines. Hautes Eludes Commercials, Montréal, Québec, Canada, Transportation, 1975. 9(2): p. 115-121.

[46] Marguier, P. and A. Ceder, Passenger Waiting Strategies for Overlapping Bus Routes. Massachusetts Institute of Technology, Cambridge, Massachusetts, Transportation Science, 1984. 18(3): p. 207-230.

[47] Hadas, Y. and M. Shnaiderman, Public-transit frequency setting using minimum-cost approach with stochastic demand and travel time. Transportation Research Part B: Methodological, 2012. 46(8): p. 1068-1084.

[48] Guihaire, V. and J.-K. Hao, Transit network design and scheduling: A global review. Transportation Research Part A, 2008. 42: p. 1251-1273.

[49] Spiess, H., On optimal route choice strategies in transit networks. Publication 285, Centre de Recherche sur les Transports, Université de Montréal, 1983.

[50] Cea, J.D. and E.Fernandez, Transit assignment for congested public transport system: An equilibrium model. Transportation Science, 1993. 27(133-147).

[51] Zhao, F., Large-scale transit network optimization by minimizing transfers and user cost. Journal of Public Transportation, 2006. 9(2): p. 107-129. 